\title{
Prophylactic magnesium sulphate in severe preeclampsia- Loading dose only vs. conventional 24 hour therapy of modified Pritchard's regime- A randomised trial.
}

\author{
Hethyshi Ranganna ${ }^{1,}$ S.C. Saha ${ }^{2,}$ Meenakshi Rohilla Thami ${ }^{3,}$ Praveen Kumar $^{4}$ \\ ${ }^{1}$ - Assistant Professor, Dept of OBG, KIMS Hospital, Bangalore \\ 2 - Additional Professor, Dept of OBG, PGIMER, Chandigarh \\ ${ }^{3}$ - Assistant Professor, Dept of OBG, PGIMER, Chandigarh \\ ${ }^{4}$ - Professor, Dept of Pediatrics, PGIMER, Chandigarh
}

\begin{abstract}
Objective: To determine the efficacy and safety of only the loading dose of modified Pritchard's regime of magnesium sulphate therapy in patients of severe preeclampsia. Method: Patients of severe preeclampsia were randomly allocated to study group $(n=50)$ and control group $(n=50)$ based on computer generated random numbers. Patients in the study group received only the loading dose of magnesium sulphate and patients in the control group received the loading dose of magnesium sulphate followed by the maintainance dose every fourth hourly. Patients in both the groups were monitored closely after the initiation of therapy. Chi-square test and Student's t test was used for data analysis. Results: There was one case of seizure in each group $(2 \%)$.There were 6 cases of absent knee jerk and 4 cases of oliguria in those receiving the 24 hour magnesium sulphate while none of these complications were seen in those receiving only the loading dose ( $p=$ $0.012, p=0.022)$.Neonatal mortality was more in the control group $(p=0.071)$ Conclusion: The loading dose of the modified Pritchard's regime alone may be effective in preventing seizures in patients of severe preeclampsia with the added advantage of reduced toxicity and better neonatal outcome.
\end{abstract}

KEYWORDSS: evere preeclampsia; Prophylactic magnesium sulphate; Loading dose of modified Pritchard's regime; Efficacy and toxicity

\section{INTRODUCTION}

Preeclampsia and eclampsia are important causes of maternal morbidity and mortality, more so in the developing countries $(1,2)$. Together preeclampsia-eclampsia account for 40,000 maternal deaths every year with most of the mortalities occurring in the developing countries(3). In India, they account for $5 \%$ of all maternal deaths with most of them occurring due to eclampsia(4). Seizure prevention is an integral part of preeclampsia management apart from the control of blood pressure and delivery of the feto - placental unit. Magnesium sulphate is the drug of choice for women with eclampsia(5) although its use is fraught with many uncertainties. The conventional regime of magnesium sulphate is an empirical approach developed over the years based on its clinical efficacy. These regimes which were initially used for the treatment of eclampsia were empirically extended to the management of preeclampsia, although the rationale was unclear. Later studies confirmed the efficacy of magnesium sulphate in preventing seizures in patients of preeclampsia $(6,7,8)$. With the breakthrough study of the Magpie trial ${ }^{7}$ showing a reduction of up to $58 \%$ in the incidence of seizures in the patients of preeclampsia, magnesium sulphate became the drug of choice even in the management of preeclampsia. However there are no standard recommendations as yet regarding the optimal time to initiate the therapy, the dose and the dosing schedule to be used, the route of administration and the duration of therapy. Even in the Magpie trial there was diversity in the use of magnesium sulphate depending on the various trial centres. Doses of magnesium sulphate used in the prophylactic treatment were similar to those used in the treatment of eclampsia. Furthermore with a randomised controlled trial showing that seizures can be effectively controlled in cases of eclampsia by giving only the loading dose(9) it can be hypothesised that there is role of less doses of magnesium sulphate than the existing regimes in the prevention of seizures in patients of severe preeclampsia. Only very few studies have been conducted in patients of preeclampsia to elucidate the efficacy of lower doses of magnesium sulphate in prevention of seizures $(10,11)$. While results of these studies are encouraging, there is definitely scope for probing further to find out the least possible dosing schedule that can effectively prevent the occurrence of seizures in patients of preeclampsia. In a developing countries where the maternal morbidity due to preeclampsia-eclampsia is relatively higher, resorting to shorter courses of therapy with 
minimal monitoring would be a boon to the peripheral health centres with poor resources. The present study explores one such possibility; by comparing the safety and efficacy of a single loading dose of modified Pritchard's regime of magnesium sulphate with that of the conventional modified Pritchard's regime of magnesium sulphate therapy which is continued till 24 hours postpartum in patients of severe preeclampsia.

\section{MATERIALS AND METHOD}

The study was conducted in the department of Obstetrics and Gynaecology Nehru Hospital, affiliated to Postgraduate Institute of Medical Education and Research, Chandigarh. It was approved by the ethical committee of the institution. Patients admitted in the labor room were recruited to the study based on ACOG criteria for severe preeclampsia(13) after taking their written consent. Preeclampsia was considered to be severe if one or more of the following criteria was present(13). Blood pressure of $160 \mathrm{~mm} \mathrm{Hg}$ systolic or higher or $110 \mathrm{~mm} \mathrm{Hg}$ diastolic or higher on two occasions at least 6 hours apart, Proteinuria of $5 \mathrm{~g}$ or higher in a 24 hour urine specimen or $3+$ or greater on two random urine samples collected at least 4 hours apart, Oliguria of less than $500 \mathrm{ml}$ in 24 hours, Impaired liver function test, thrombocytopenia (platelets $<1.5 \mathrm{lakh} / \mathrm{mm}^{3}$ ), cerebral or visual disturbances, epigastric or right upper quadrant pain. Patients with platelet count $<50,000 / \mathrm{mm}^{3}$, plasma creatinine concentration $>/=2 \mathrm{mg} / \mathrm{dl}$, pulmonary edema and comatose patients were excluded from the study. One hundred and two patients of severe preeclampsia fulfilling the inclusion and exclusion criteria were randomly allocated to the study and control group by using computer generated random numbers. Out of the 52 patients in the control group two patients quit the study as they wanted to go to another health centre. Detailed history and complete examination of the patients was done at the time of admission. Complete blood counts, coagulogram, liver and renal function tests and urine protein levels were estimated. Modified Pritchard regimen(12) was used in the control group. All patients in the control group received a loading dose of $4 \mathrm{gm}$ magnesium of sulphate intravenously as a $20 \%$ solution and $8 \mathrm{gm}$ as a $50 \%$ solution intramuscularly, $4 \mathrm{gm}$ in each buttock. All patients were catheterised and hourly urine output was recorded. A maintenance dose of $4 \mathrm{gm}$ of magnesium sulphate as a 50\% solution was administered intramuscularly every four hours in alternate buttocks. Before each maintenance dose of magnesium sulphate knee jerk, respiratory rate and urine output were observed. Maintenance dose was deferred in the presence of absent knee jerk, respiratory rate less than 16/mt, urine output less than $100 \mathrm{ml}$ over 4 hours. The patients in the study group received only the loading dose of a $20 \%$ solution of $4 \mathrm{~g}$ of magnesium sulphate intravenously followed by $50 \%$ solution of $4 \mathrm{~g}$ magnesium sulphate intramuscularly in each buttock. All the patients were monitored for their blood pressure, respiratory rate, urine output and emergence of the signs and symptoms of impending eclampsia like persistent headache, visual disturbances, epigastric or right upper quadrant pain or tenderness. Appearance or persistence of the signs and symptoms of impending eclampsia or occurrence of seizures after the administration of the loading dose, was considered as cases of failure of the loading dose regime and patients were switched over to the standard modified Pritchard regime as in the control group. The antihypertensives used were oral sustained release nifedipine, alpha methyl dopa, labetalol as per the management protocol practised in our hospital. Uncontrolled hypertension where the diastolic BP shoots up $>110 \mathrm{mmHg}$ was controlled by oral plain nifedipine or intravenous labetalol. Patients under study were either induced, allowed for spontaneous labour or conservative management was followed in some depending on the clinical situation. The mothers were kept under close observation at least $48-72$ hours post partum and discharged thereafter. The neonates were followed up till discharge from the hospital. The primary outcome was the occurrence of seizures in the mothers. The secondary outcomes assessed were conversion to the standard regime due to persistence of signs and symptoms of impending eclampsia, signs of magnesium intoxication like loss of knee jerk, decreased urine output, incidence of placental abruption and postpartum hemorrhage. Neonatal outcomes were assessed by Apgar scores at 1 and 5 minutes, respiratory depression needing intubation at the time of delivery, nursery admissions, incidence of hypoxic ischemic encephalopathy, cord blood $\mathrm{pH}$ and mortality. Categorical data was analysed using the chi-square test and normally distributed continuous variables were analysed with student's $t$ test. A probability value of $<0.05$ was considered significant

\section{RESULTS}

During the study period of 15 months, 50 patients of severe preeclampsia under the control group received the conventional 24 hour regime of magnesium sulphate and 50 patients of severe preeclampsia under the study group received only the loading dose of magnesium sulphate. The total no of patients enrolled and their details is depicted in the flow diagram. 


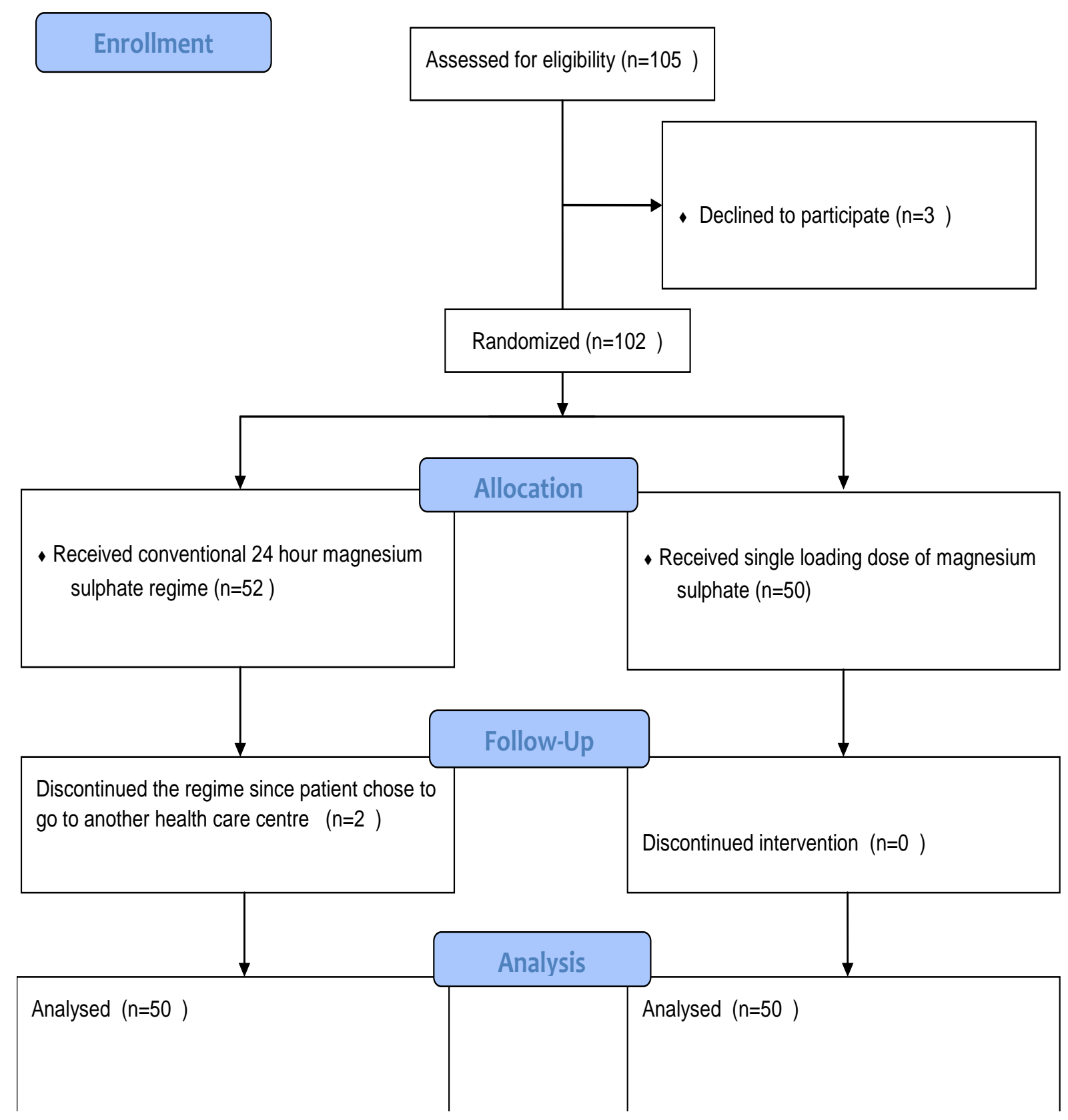

The baseline characteristics of the patients is depicted in table 1. Patients in both the groups were comparable in terms of age, number of previous pregnancies and period of gestation. The distribution of patients based on blood pressure and albuminuria is depicted in table 2 and 3 . There were lesser number of patients with systolic BP > 160mmHg in the study group which was statistically significant but there was no such significant difference seen in the distribution of diastolic blood pressure. Maternal morbidity noted after the initiation of prophylactic magnesium 
Table 1: Baseline patient characteristics

\begin{tabular}{|c|c|c|c|}
\hline Categorical variables & $\begin{array}{l}\text { Modified } \\
\text { Pritchard's }\end{array}$ & $\begin{array}{l}\text { Loading } \\
\text { dose only }\end{array}$ & $P$ - value \\
\hline Age group(Years) & & & \multirow{4}{*}{0.956} \\
\hline $19-20$ & $04(8)$ & $04(8)$ & \\
\hline $21-30$ & $39(78)$ & $40(80)$ & \\
\hline $31-40$ & $07(14))$ & $6(12)$ & \\
\hline Mean age & $\begin{array}{c}25.60+/- \\
3.67\end{array}$ & $\begin{array}{c}25.76+/- \\
4.86\end{array}$ & 0.853 \\
\hline Gravida-Status & & & \multirow{5}{*}{0.374} \\
\hline Primigravida & $29-(58)$ & $32-(64)$ & \\
\hline Gravida-II & $14-(28)$ & $14-(28)$ & \\
\hline Gravida-III & 04-(8) & 04-(8) & \\
\hline Gravida-IV & Nil & Nil & \\
\hline Gestation in Weeks & & & \\
\hline $26-28$ & & $2-(4)$ & \multirow{4}{*}{0.358} \\
\hline $28-32$ & & 11-(22) & \\
\hline $33-36$ & $24-(48)$ & 19-(38) & \\
\hline$\geq=37$ & 10-(20) & 18-(36) & \\
\hline Mean gestation & $31.56 \pm 3.27$ & $31.28 \pm 3.47$ & 0.533 \\
\hline
\end{tabular}

Table 2 : Maximum systolic and diastolic blood pressure

\begin{tabular}{|l|c|c|c|}
\hline $\begin{array}{l}\text { Maximum systolic } \\
\text { BP in mm of Hg }\end{array}$ & $\begin{array}{c}\text { Modified Pritchard's } \\
(\mathbf{n = 5 0})(\%)\end{array}$ & $\begin{array}{l}\text { Loading dose only } \\
(\mathbf{n = 5 0}(\boldsymbol{\%})\end{array}$ & p- value \\
\hline$</=160$ & $26(52)$ & $38(77.6)$ & $\mathbf{0 . 0 0 8}$ \\
\hline$>160$ & $24(48)$ & $11(22.4)$ & \\
\hline
\end{tabular}

\begin{tabular}{|c|c|c|c|}
\hline $\begin{array}{l}\text { Maximum diastolic BP } \\
\text { in mm of Hg }\end{array}$ & $\begin{array}{c}\text { Modified Pritchard's } \\
(\mathbf{n}=\mathbf{5 0})(\%)\end{array}$ & $\begin{array}{c}\text { Loading dose only } \\
(\mathbf{n}=\mathbf{5 0})(\%)\end{array}$ & p- value \\
\hline$</=110$ & $32(64)$ & $36(73.5)$ & $\mathbf{0 . 3 1 0}$ \\
\hline$>110$ & $18(36)$ & $13(26.5)$ & \\
\hline
\end{tabular}


Table 3 : Albuminuria

\begin{tabular}{|c|c|c|}
\hline $\begin{array}{l}\text { Grading of urine } \\
\text { albumin }\end{array}$ & $\begin{array}{c}\text { Modified Pritchard"s } \\
(\mathbf{n = 5 0})(\%)\end{array}$ & $\begin{array}{c}\text { Loading dose only } \\
(\mathbf{n}=\mathbf{5 0})(\%)\end{array}$ \\
\hline $1+$ & $5(10)$ & $6(12)$ \\
\hline $2+$ & $12(24)$ & $12(24)$ \\
\hline $3+$ & $11(22)$ & $10(20)$ \\
\hline $4+$ & $22(44)$ & $20(40)$ \\
\hline
\end{tabular}

p value -0.693

Table 4: Maternal morbidity

\begin{tabular}{|l|c|c|}
\hline & $\begin{array}{c}\text { Modified } \\
\text { Pritchard's } \\
(\mathbf{n = 5 0})(\%)\end{array}$ & $\begin{array}{c}\text { Loading dose } \\
\text { only } \\
(\mathbf{n = 5 0})(\%)\end{array}$ \\
\hline $\begin{array}{l}\text { OCCURENCE OF FIT } \\
\text { (primary outcome) }\end{array}$ & $01(2)$ & $01(2)$ \\
\hline $\begin{array}{l}\text { Conversion to control } \\
\text { regime }\end{array}$ & $01(2)$ & 0 \\
\hline Anaesthesia complications & $01(2)$ & $01(2)$ \\
\hline Postpartum psychosis & 0.00 & $01(2)$ \\
\hline Switch over to Phenytoin & 0.00 & $01(2)$ \\
\hline Placental abruption & $02(4)$ & $06(12)$ \\
\hline Post partum haemorrhage & $02(4)$ & $03(6)$ \\
\hline HELLP syndrome & $01(2)$ & $02(4)$ \\
\hline
\end{tabular}

Table 5: Morbidity due to use of magnesium sulphate

\begin{tabular}{|l|c|c|l|}
\hline Morbidity & $\begin{array}{l}\text { Modified Pritchard's } \\
(\mathbf{n}=50)(\%)\end{array}$ & $\begin{array}{l}\text { Loading dose only } \\
(\mathbf{n}=\mathbf{5 0})\end{array}$ & $\boldsymbol{p}$-value \\
\hline Absent knee jerk & $6(12)$ & 0 & 0.012 \\
\hline Oliguria & $5(10)$ & 0 & 0.022 \\
\hline
\end{tabular}


Table 6: Perinatal outcome

\begin{tabular}{|c|c|c|c|}
\hline & $\begin{array}{l}\text { Modified } \\
\text { Pritchard's } \\
(n=52)(\%)\end{array}$ & $\begin{array}{l}\text { Loading dose } \\
\text { only } \\
(n=52)(\%)\end{array}$ & p-value \\
\hline Live born & $43(82.69)$ & $47(90.38)$ & 0.566 \\
\hline $\begin{array}{l}\text { Fresh still born } \\
\text { Cause of still birth }\end{array}$ & $\begin{array}{l}\quad 6(11.53) \\
\text { LBW }-3 \\
\text { Abruption }-1 \\
\text { Congenital heart } \\
\text { block -1 } \\
\text { Unknown cause - } 1\end{array}$ & $\begin{array}{l}\qquad 4(7.69) \\
\text { Prematurity }-1 \\
\text { Associated } \\
\text { abruption in } 2\end{array}$ & \\
\hline Macerated still born & $3(5.76)$ & $1(0.01)$ & \\
\hline Mean POG at birth (weeks) & $34.5+/-3.3$ & $34.4+/-3.1$ & \\
\hline Apgar $<7$ at $1 \mathrm{mt}$ & 17(33.3) & $12(22.6)$ & \\
\hline Apgar $<7$ at 5 mt & $11(21.50)$ & $10(19.23)$ & 0.544 \\
\hline $\begin{array}{l}\text { Respiratory depression requiring } \\
\text { intubation }\end{array}$ & $11(21.50)$ & $8(15.38)$ & 0.393 \\
\hline Birth weight $<-2$ SD & $9(17.30)$ & $6(11.53)$ & \\
\hline $\begin{array}{l}\text { Admission to special neonatal } \\
\text { care unit }\end{array}$ & $10(19.23)$ & $17(32.69)$ & 0.224 \\
\hline Hypoxic ischemic encephalopathy & $6(11.53)$ & $3(5.76)$ & 0.268 \\
\hline Mortality & $\begin{array}{l}7(13.46) \\
\text { HIE }-4 \\
\text { Sepsis - } 3\end{array}$ & $\begin{array}{l}2(3.84) \\
\text { Sepsis - } 3\end{array}$ & 0.071 \\
\hline
\end{tabular}

sulphate is delineated in table 4 and 5. One patient in the study group and one patient in the control group threw a fit when on therapy. One patient in the study group developed signs and symptoms of impending eclampsia some time after receiving the loading dose and was started on 24 hour regime similar to the control group for the benefit of the patient. One patient in the control group was switched over to phenytoin therapy because of recurrent convulsions with magnesium sulphate therapy as advised by the neurologist.There was one maternal mortality in the study group after few hours following delivery due to amniotic fluid embolism.

The babies born to patients in both the groups were followed up till discharge from the hospital. Out of the 43 live born babies in the control group 10 babies needed intensive care and out of the 47 live born babies in the study group 17 babies needed intensive care. There were 7 neonatal deaths in the control group and only 2 neonatal deaths in the study group. The perinatal outcome is depicted in table 6.

\section{DISCUSSION}

Magnesium sulphate is the drug of choice for seizure prophylaxis in patients of severe preeclampsia(7). World over different regimes are being used. Our study compared the efficacy and safety of Modified Pritchard's regime(12) with the loading dose alone being given. In our study there was one case of seizure in each of the groups. The seizure in the study group occurred 6 hours after the loading dose of magnesium sulphate was given. The patient in the control group who was on the conventional 24 hour regime of magnesium sulphate had a seizure after 2 and a half hour after the $3^{\text {rd }}$ maintenance dose. One case in the study group (2\%) required conversion to the control group regime due to the development of features of impending eclampsia for the benefit of the patient. 
Four randomised controlled trials that compared the use of no magnesium sulphate or a placebo vs magnesium sulphate to prevent convulsions in patients of severe preeclampsia showed that the rate of eclampsia was $0.6 \%$ among 6343 patients assigned to magnesium sulphate vs $2.0 \%$ among 6330 patients assigned to placebo or control (RR 2.06; 95\% CI 1.33-3.18) ${ }^{14}$.So $100 \%$ prevention of seizures is not possible even with the standard regimes of magnesium sulphate. The present concept is that seizure control would be an individual response than either the result of achieving fixed drug serum levels or the dosage of the $\operatorname{drug}^{15}$. So tailoring the administration of the drug to an individual patient as per her need would be an ideal approach for effective seizure prophylaxis and management. This led to studies using clinical parameters to decide on the duration of magnesium sulphate therapy in patients of severe preeclampsia $(16,17)$. On the other hand different studies were conducted to find out the least effective dosage of the drug which could simultaneously reduce the toxicity associated with the $\operatorname{drug}(10,11)$. Our study was designed such that after an initial loading dose, subsequent doses of the drug were to be administered only if the patient developed any features of impending eclampsia. Patients of mild preeclampsia were excluded since the number of patients needed to treat would be more(7) and the available evidence regarding the benefit to risk ratio of magnesium sulphate prophylaxis in mild preeclampsia remains uncertain $(18,19)$. In the Magpie trial the incidence of seizures in patients of severe preeclampsia including those with impending eclampsia $(n=2174)$ receiving the placebo was $3.12 \%$. This risk was reduced to $1.09 \%$ in patients of severe preeclampsia including those with impending eclampsia $(n=2107)$ who were given magnesium sulphate. The trial concluded that there was a reduction of $58 \%$ in the risk of occurrence of seizures regardless of the severity of the disease by using magnesium sulphate. In our study the risk of occurrence of seizures was similar in both the groups. Fontenot et al used postpartum diuresis as a criteria for the cessation of magnesium sulphate therapy in patients of severe preeclampsia and compared the outcome with patients receiving magnesium sulphate for 24 hours post partum. There was a significant reduction in the duration of post partum magnesium sulphate therapy with no untoward outcome or need for reinitiation of the therapy(17). Our study was also aimed at reducing the duration of the therapy in patients of severe preeclampsia by using only the loading dose of magnesium sulphate. The loading dose alone was found to be equally effective in preventing seizures as the continuous 24 hour regime. Our study demonstrated a significant reduction in the toxicity associated with the use of magnesium sulphate in the study group in comparison to the control group. There was a significant difference seen between the two groups in terms of absent knee jerk $(\mathrm{p}=0.01)$ and oliguria $(\mathrm{p}=0.02)$. However the Magpie trial $(16)$ did not demonstrate any difference between the patients on magnesium sulphate and those receiving the placebo in terms of absent knee $(0.93 \% \mathrm{v} / \mathrm{s} 0.98 \%)$ and oliguria $(2.26 \% \mathrm{v} / \mathrm{s} 2.93 \%)$. These complications of magnesium sulphate though were not grave they mandate close observations to avoid fatal complications like respiratory arrest and cardiac arrest associated with its use. There were a total of $8.2 \%$ still births in the patients on magnesium sulphate $(\mathrm{n}=4538)$ and $8.6 \%$ in those receiving placebo $(\mathrm{n}=4486)$ and the early neonatal deaths were $3.2 \%$ and $2.9 \%$ respectively in the Magpie trial. The effect on baby death was consistent regardless of the severity of preeclampsia. However recent studies have shown that the perinatal mortality and morbidities are relatively more in severe preeclampsia than in mild preeclampsia(20). Study by Noor et al where loading dose of the standard Pritchard's regime was used had a still birth rate of $15 \%$, neonatal death rate of 5\% and perinatal mortality of $35.8 \%$ in patients of preeclampsia. Neonatal outcome was better in our study with a still birth rate of $7.7 \%$, neonatal death rate of $3.84 \%$ and perinatal mortality of $11.54 \%$ in the study group, which received only the loading dose of the modified Pritchard's regime. Between both the groups in our study, the study group which employed a truncated regime had better perinatal outcome than the control group however only the incidence of neonatal death was statistically significant.

Our study was designed mainly for the peripheral health centres with minimal facilities which could conveniently use the loading dose regime for preventing seizures before referring to higher centres. The efficacy of the loading dose in preventing seizures was similar to the control group with one patient in both the groups throwing a fit. The sample size of the study being small significance of the results of the study cannot be ascertained. But the findings of the study are encouraging for similar studies with large sample size.

Various studies on use of Magso4 in severe preeclampsia including the popular Magpie trial have confirmed the decrease in incidence of seizures in patients of severe preeclampsia with the use of Magso4 but none have found a $100 \%$ decrease in incidence of seizures. So the mystery remains unsolved regarding the ideal dosage of Magso4 to be used for seizure prophylaxis. Our study is about one of the many possible variations with the dosing of Magso4 that could be effective and safe. This warrants large randomised multicentric trials to increase the confidence in the results of this study. 


\section{CONCLUSION}

The efficacy of a single loading dose of magnesium sulphate in prevention of seizures was similar to the conventional 24 hour regime though not superior to it. There was a trend towards decreased side effects of magnesium sulphate in the group which received only the loading dose. Hence it would be useful in peripheral health centers without good monitoring facility. Further the neonatal morbidity and mortality was more in the control group. However this study is a pilot study and multicentric studies with larger sample size are warranted to increase the confidence in the results of this study.

\section{Funding}

No financial support was taken for this study.

\section{ACKNOWLEDGMENT}

We take this opportunity to thank all the patients and the staff who cared for these patients.

\section{BIBLIOGRAPHY}

1. Melah GS, Massa AA, El-Nafaty AU. Pregnancy outcomes of women with eclampsia in Gombe, Nigeria. Int J Gynecol Obstet 2006;92:251-52.

2. Duley L. Maternal mortality associated with hypertensive disorders of pregnancy in Africa, Asia, Latin America and the Caribbean. Br J Obstet Gynecol 1992;99:547-53.

3. Villar J, Say L, Shennan A, Lindheimer M, Duley L, Conde-Agudelo A et al.

Methodological and technical issues related to the diagnosis, screening, prevention and treatment of pre-eclampsia and eclampsia. Int J Gynecol Obstet 2004;85 Suppl 1 : S2841.

4. Govt. of India (sample registration system), Maternal mortality in India: 1997-2003, Trends, causes and risk factors, Registrar General, India, New Delhi in collaboration with Centre for Global Heart Research University of Toronto, Canada.

5. The Eclampsia Trial Collaboraive Group. Which anticonvulsant for women with eclampsia? Evidence from the Collaborative Eclampsia Trial. Lancet 1995;345:1455-63.

6. Coetzee EJ, Dommisse J, Anthony J. A randomised controlled trial of intravenous magnesium sulphate versus placebo in the management of women with severe preeclampsia. Br J Obstet Gynecol 1998;105:300-03.

7. Do women with pre-eclampsia, and their babies, benefit from magnesium sulphate? The Magpie Trial: a randomised placebo- controlled trial. Lancet 2002;359:1877-1890.

8. Belfort MA, Anthony J, Saade GR, Allen JC. A comparison of magnesium sulfate and nimodipine for the prevention of eclampsia. N Eng J Med 2003;348:304-11.

9. Mosammat Rashida Begum, Anowara Begum, Ehsan Quadir . Loading dose versus standard regime of magnesium sulphate in the management of eclampsia : A randomised trial . Obstet gynaecol 2002;28:154-59.

10. Suman S, Shinanjalin M, Ajit P, Uday P. Low dose magnesium sulphate therapy for eclampsia and imminent eclampsia: Regimen tailored for Indian women.

J Obstet Gynecol indi 2003; 55:546-550.

11. Noor S, Halimi M, Faiz N R, Akbar N. Magnesium sulphate in the prophylaxis and treatment of eclampsia. J Ayub Med Coll Abbottabad;16(2).

12. Bhalla AK, Dhall GI, Dhall K. A safer and more effective treatment for eclampsia. Aust N J Obstet Gynaecol 1994; 34: 144-148. 
13. American College of Obstetrician and Gynaecologists. Diagnosis and management of preeclampsia and eclampsia. ACOG practice bulletin no:33. Obstet Gynecol 2002;99:159-165.

14. Sibai BM. Magnesium sulfate prophylaxis in preeclampsia: Lessons learned from recent trials. Am J Obstet Gynecol 2004; 190: 1520-1526.

15. Sibai BM, Lipshitz J, Anderson GD, Dilts PV. Reassessmant of intravenous MgSO4 therapy in reeclampsia-eclampsia. Obstet Gynecol 1981; 57: 199-202.

16. Ascarelli MH, Johnson V, May WL, Martin RW, Martin JN Jr. Individually determined postpartum magnesium sulfate therapy with clinical parameters to safely and cost -effectively shorten treatment for preeclampsia. Am J Obstet Gynecol 1998; 179: 952-956.

17. Fontenot MT, Lewis DF, Frederick JB, Wang Y, Defranco EA, Groome LJ, Evans AT. A prospective randomised trial of magnesium sulfate in severe preeclampsia: Use of diuresis as a clinical parameter to determine the duration of postpartum therapy. Am J Obstet Gynecol 2005; 192: 1784-1794.

18. Livingston JC, Livingston LW, Ramsay R, Mabie BC, Sibai BM. Magnesium sulfate in women with mild preeclampsia: A randomised controlled trial.

19. Witlin AG, Friedman SA, Sibai BM. The effect of magnesium sulfate on the duration of labor in women with mild preeclampsia at term: a randomised, double blind, placebo controlled trial. Am J Obstet Gynecol 1997; 176: 623-627.

20. Buchbinder A, Sibai BM, Claritis S, et al. Adverse perinatal outcomes are significantly higher in severe gestational hypertension than in mild preeclampsia. Am J Obstet Gynecol 2002;186:66. 